\title{
Conventional tissue culture compared with rapid immunofluorescence for identifying Chlamydia trachomatis in specimens from patients attending a genitourinary clinic
}

Address for reprints: Dr E L Teare, Public Health Laboratory, Dulwich Hospital, East Dulwich Grove, London SE22 8QF

Accepted for publication 11 March 1985 immunofluorescence technique was highly specific and slightly more sensitive than tissue culture. In addition, they found it quicker and simpler.

The aims of the present study were: firstly, to assess the incidence of chlamydial infection at the Alexanda Clinic, Kings College Hospital, London (the genitourinary department for the Camberwell Health Authority, which serves a resident population of around 227 000.) Secondly, we aimed to compare the tissue culture and immunofluorescence methods in the context of a busy clinic.

\section{Patients and methods}

STUDY POPULATION

The population studied consisted of consecutive patients attending the Alexanda Clinic who either had signs and symptoms of chlamydial infection or were known contacts of men with non-gonococcal urethritis (NGU). Presenting features in the women included cervicitis, mucopurulent discharge (with no Gram negative diplococci seen in Gram stained endocervical specimens), and lower abdominal pain with clinical pelvic inflammatory disease. All the men in the study were diagnosed as suffering from NGU on clinical grounds and had $>5$ pus cells per high power field (magnification $\times 1000$ ) in Gram stained urethral smears. 


\section{COLLECTION OF SPECIMENS}

Men

We took urethral swabs for microscopy and culture for Ngonorrhoeae with $1 \mu$ linoculating loops(NUNC Products, Kamstrup, Denmark). Specimens for gonococcal culture were directly plated on to ThayerMartin medium (Southern Group Laboratory, London, England). A sterile pernasal swab (Medical Wire \& Equipment Co, Corsham, Wiltshire, England) was used for collecting specimens to identify $C$ trachomatis. Swabs were inserted a few centimetres into the urethra and rotated several times. The swab was then rolled over a circular area ( $4 \mathrm{~mm}$ in diameter) of a teflon coated slide, which was checked for even coverage of material left on the slide. Finally, the swab was placed in a bijoux bottle containing $3 \mathrm{ml}$ of chlamydia transport medium. The transport medium consisted of Eagle's minimum essential medium supplemented with $0 \cdot 13 \%$ sodium bicarbonate, $10 \%$ fetal calf serum, $0 \cdot 5 \%$ glucose, and additional amino acids, vitamins, and glutamine. It contained gentamicin (10 mg/l) and amphotericin B (2.5 mg/l).

\section{Women}

The cervical area was first cleared of excess mucus and exudate with a large cotton wool swab. We then used $10 \mu \mathrm{l}$ inoculating loops (NUNC) to obtain urethral and cervical specimens for microscopy, wet preparations for Trichomonas vaginalis, and endocervical specimens for $N$ gonorrhoeae culture, directly inoculated on to Thayer-Martin media. Finally, a cotton wool swab was inserted into the endocervical canal, rotated for five to 10 seconds, and withdrawn without touching the vaginal surface. This swab was rolled on to a teflon coated slide and placed in chlamydia transport medium as described for the men. Thayer-Martin plates were incubated in a candle jar with $2 \%$ carbon dioxide at $37^{\circ} \mathrm{C}$ until transported to the laboratory.

Slides were air dried and flooded with acetone, which was allowed to evaporate. When completely dried, the slides were placed in a slide box. All specimens were kept at $4^{\circ} \mathrm{C}$ for a maximum of 18 hours before transport to the laboratory. On receipt in the laboratory swabs were stored at $4^{\circ} \mathrm{C}$ if they were to be inoculated on the day of receipt or stored in liquid nitrogen (at $-192^{\circ} \mathrm{C}$ ) if inoculation was to occur subsequently. Slides were held at $-70^{\circ} \mathrm{C}$ if not examined on the day of receipt.

CHLAMYDIAL ISOLATION

Isolation was attempted in McCoy cells grown on $13 \mathrm{~mm}$ coverslips in culture tubes, each coverslip being seeded with $5 \times 10^{4}$ cells. The McCoy cells were seeded in growth medium (Eagle's minimum essential medium containing $10 \%$ fetal calf serum, $0 \cdot 11 \%$ bicarbonate, $10 \mathrm{mg} / 1$ gentamicin, and additional amino acids, vitamins, and glutamine) containing $25 \mathrm{mg} / \mathrm{l}$ idoxuridine and were incubated for two days before use. ${ }^{10}$ For isolation, the growth medium was removed, replaced with $1 \mathrm{ml}$ of the specimen, and centrifuged at $3000 \times g$ for one hour at $35^{\circ} \mathrm{C}$. After further incubation for two hours at $35^{\circ} \mathrm{C}$, the supernatant was removed and replaced with fresh growth medium containing idoxuridine. Tubes were incubated for a further two to three days before the coverslips were fixed with methanol and stained with iodine. $C$ trachomatis was considered to be present if characteristic intracytoplasmic inclusions were seen. All specimens were examined by the same observer (CS).

\section{EXAMINATION OF SLIDES}

Fixed slides were allowed to reach room temperature, and $15 \mu$ l of direct monoclonal antibody (MicroTrak, Syva, Palo Alto, California, United States of America) was spread on the smear. The slide was incubated at room temperature in a moist chamber for 15 minutes. Reagent was removed by immersing the slide in distilled water for 10 seconds, excess water being absorbed by blotting round the smear with filter paper. Finally, the slide was allowed to dry at room temperature. The smear was mounted under a coverslip with MicroTrak chlamydia direct specimen mounting fluid and examined with a polyvar immunofluorescence microscope (Reichert-Jung). We used a B1 filter block epi-illumination system with $\times 10$ magnification eye pieces, a $\times \mathbf{4 0}$ magnification aperture, and with $\times 1 \cdot 25$ intermediate magnification. All slides were examined by one observer (CS).

\section{STATISTICAL COMPARISON}

We used the following definitions: true positives (results positive by both methods), true negatives (results negative by both methods), false positives (results positive by test method and negative by standard method), and false negatives (results negative by test method and positive by standard method).

We defined sensitivity as:

true positives

true positives plus false negatives

and specificity as:

true negatives

true negatives plus false positives

We calculated the probability value using the $\chi^{2}$ test. 
Results

A total of 216 patients (93 men, 123 women) entered the study. Thirty four (19 men and 15 women) were excluded from the analysis; 24 because of insufficient material on the slides to perform the immunofluorescence tests, seven because of contaminated tissue culture cells, and three because specimens failed to reach the laboratory. The table summarises the presenting clinical features and may not return. With an "on site" immunofluorescence service, a result could be available within $\mathbf{4 0}$ minutes. If there is sufficient clinical awareness for patients to be treated on clinical grounds, then a tissue culture method may suffice if that is deemed necessary. The avoidance of delay in diagnosis and effective treatment of patients and sexual contacts is, however, of paramount importance. A rapid diagnostic method will undoubtedly be more efficient in achieving this.

TABLE Summary of presenting clinical features and microbiological results of culture and immunofluorescence

\begin{tabular}{|c|c|c|c|c|c|c|}
\hline \multirow[b]{2}{*}{ Clinical diagnosis } & \multicolumn{4}{|c|}{ No of patients positive by: } & \multicolumn{2}{|c|}{ No (\%) positive by: } \\
\hline & $\begin{array}{l}\text { Both } \\
\text { methods }\end{array}$ & $\begin{array}{l}\text { Culture } \\
\text { only }\end{array}$ & $\begin{array}{l}\text { Immunofluores- } \\
\text { cence only }\end{array}$ & $\begin{array}{l}\text { Neither } \\
\text { method }\end{array}$ & $\begin{array}{l}\text { Both } \\
\text { methods }\end{array}$ & $\begin{array}{l}\text { One or both } \\
\text { methods }\end{array}$ \\
\hline $\begin{array}{l}\text { Cervicitis and vaginal } \\
\text { discharge }(\mathrm{n}=17) \\
\text { Pelvic inflammatory }\end{array}$ & 7 & 0 & 1 & 9 & $7(41)$ & $8(47)$ \\
\hline & 28 & 0 & 4 & 13 & $28(62)$ & $32(71)$ \\
\hline $\begin{array}{c}\text { with NGU }(n=46) \\
\text { Men with NGU }(n=74)\end{array}$ & $\begin{array}{l}20 \\
48\end{array}$ & $\begin{array}{l}0 \\
1\end{array}$ & $\begin{array}{l}1 \\
7\end{array}$ & $\begin{array}{l}25 \\
18\end{array}$ & $\begin{array}{l}20(43) \\
48(65)\end{array}$ & $\begin{array}{l}21(46) \\
56(76)\end{array}$ \\
\hline Total $(n=182)$ & 103 & 1 & 13 & 65 & $103(57)$ & $117(64)$ \\
\hline
\end{tabular}

NGU = non-gonococcal urethritis.

microbiological results obtained in the remaining 182 patients. The difference between the two tests in detecting $C$ trachomatis was not significant $(p>0 \cdot 1)$. If tissue culture was taken to be the reference method, the sensitivity of the immunofluorescence test was $99 \%$ and the specificity $83 \%$.

\section{Discussion}

$C$ trachomatis was identified in a total of $64 \%$ of patients in this study by culture or immunofluorescence, or both. The immunofluorescence method had high sensitivity but only moderate specificity compared with the standard culture method, a finding that other workers have shown. ${ }^{11}$ This may be accounted for by detecting non-viable organisms by the immunofluorescence technique, and the apparent lack of specificity may really be due to the enhanced sensitivity of this method. Positive by both methods were: $41 \%$ of women with cervicitis and discharge, $62 \%$ of women with clinical pelvic inflammatory disease, $43 \%$ of sexual contacts of men with NGU, and $65 \%$ of men with NGU. It therefore became apparent during the course of this study that the incidence of chlamydial infection in our district was much greater than had hitherto been thought, and clinical awareness of the condition increased dramatically.

Many advantages may be gained from the use of a rapid diagnostic technique, not least because patients attending sexually transmitted disease (STD) clinics
The incidence of chlamydial infection in our study population justifies providing an identification service and, though local incidences may vary, we suspect that this is generally true. In our hands, there was no significant difference between the two methods used for identifying $C$ trachomatis, but it should be pointed out that we already had a well established tissue culture service at the start of the study. Such a service requires considerable expenditure and technical expertise, and cost analysis in an individual unit may well justify the capital outlay for a fluorescence microscope. In such an analysis, consideration must be given to factors such as possible delays between collecting specimens and inoculating tissue cultures in the laboratory. Even if transport medium is used there may be loss of viability of $C$ trachomatis and hence false negative results. None of the nursing or technical staff associated with this study found either the collection and transport of specimens or practical procedures difficult to learn effectively. The most common difficulty encountered was the finding of insufficient material on the slides for the immunofluorescence procedure. This was greatly reduced by careful instruction and explanation to those taking the specimens and occurred rarely towards the end of the study.

In this study we highlighted a need for clinical awareness of chlamydial infection and for a microbiological service to genitourinary clinics. There was no significant difference between tissue culture and immunofluorescence methods in detecting $C$ trachomatis, and the choice of method must rest with 
an analysis of cost, expertise, and practicalities in individual departments.

\section{References}

1. Dunlop EMC, Chlamydial genital infection and its complications. Br J Hosp Med 1983;29:6-11.

2. Chief Medical Officer of the DHSS. On the state of the public health for the year 1983. London: HMSO, 1984:56-60.

3. Terho P. Chlamydia trachomatis in non-specific urethritis. British Journal of Venereal Diseases 1978;54:251-6.

4. Holmes KK. The Chlamydia epidemic. JAMA 1981;245:171823.

5. Schachter J, Holt J, Goodner E, Grossman M, Sweet R, Mills J. Prospective study of chlamydial infection in neonates. Lancet 1979;ii:377-9.

6. Jones RB, Andrey BR, Hui SL, Cleary RE. Correlation between serum antichlamydial antibodies and tubal factor as a cause of infertility. Fertil Steril 1982;38:553-8.
7. Cevenini R, Possati G, LaPlaca M. Chlamydia trachomatis infection in infertile women. In: Mardh P-A, Holmes KK, Oriel JD, Piot P, Schachter J, eds. Chlamydial infections. New York, Oxford: Elsevier Biomedical Press, 1982;189-92.

8. McCormack WM, Alpert S, McCombe DE, Nichols RL Semine DZ, Zinner SH. Fifteen-month follow-up study of women infected with Chlamydia trachomatis. $N$ Eng $J$ Med 1979;300:123-5.

9. Thomas BJ, Evans RT, Hawkins DA, Taylor-Robinson D. Sensitivity of detecting Chlamydia trachomatis elementary bodies in smears by use of a fluorescein labelled monoclonal antibody: comparison with conventional chlamydial isolation $J$ Clin Pathol 1984;37:812-6.

10. Reeve $\mathbf{P}$, Owen J. Oriel JD. Laboratory procedures for the isolation of Chlamydia trachomatis from the human genital tract. J Clin Pathol 1975;28:910-4.

11. Taylor HR, Agarwala N, Johnson SL. Detection of experimental Chlamydia trachomatis eye infection in conjunctival smears and in tissue culture by use of fluoresceinconjugated monoclonal antibody. J Clin Microbiol $1984 ; 20: 392-5$. 